\title{
Dönen Makinelerde Eksenel Kaçıklık ve Dengesizliğin Titreşim Analizi
}

\author{
Necdet Alçelik ${ }^{1 *}$, Menderes Kam²
}

Revize / Revised: 08/02/2020

Kabul / Accepted: 14/02/2020

ÖZ

Dönen makine parçalarına dinamik kuvvetlerin etki etmesiyle bu parçalar üzerinde farklı frekans ve genlikte titreşim oluşabilmektedir. Çok küçük boyuttaki titreşimler rezonansa neden olurken büyük boyutlu titreşimler gürültünün oluşmasına neden olmaktadır. Dönen makine üzerinde eksen kaçıklığı ve dengesizlik ihmal edilemeyecek öneme sahip arızalardır. Eksen kaçıklığı ve dengesizliğin sebep olduğu titreşimler dönen miller aracılığ 1 ile rulmanlı yataklara aktarılır. Bu çalışmada $1380 \mathrm{~d} / \mathrm{d}$ sabit devirde dönen bir elektrik motorundan hareket alan yatak ekseni kaçık imal edilmiş bir dönen makine-mil sisteminin eksenel kaçıklığının ve dengesizliğinin titreşime olan etkileri deneysel olarak incelenmiştir. Dönen makine üzerinde 8 adet deney yapılmış ve elde edilen veriler, dört kanallı VIBROTEST 80 model FFT analizi yapabilen veri toplama cihazı ile alınmıştır. Titreşim verilerinin toplam ortalaması, kare ortalamalarının karekökü (RMS) yöntemi ile belirlenmiştir. Alınan bu veriler ışığında titreşim verilerinin tahammül edilebilir sınırlar içinde olup olmadığı değerlendirilmiştir.

Anahtar Kelimeler- Dengesizlik, Dönen Makine, Eksen Kaçıklı̆̆ı, Titreşim

1*Sorumlu yazar iletişim: nejdethredsteel@gmail.com (https://orcid.org/0000-0002-3551-826X)

Makine Mühendisliği ABD, Fen Bilimleri Enstitüsü, Düzce Üniversitesi, Düzce, Türkiye

2Iletişim: mendereskam@duzce.edu.tr (https://orcid.org/0000-0002-9813-559X)

Makine ve Metal Tek., Dr. Engin PAK Cumayeri Meslek Yüksekokulu, Düzce Üniversitesi, Düzce, Türkiye 


\title{
Vibration Analysis of Axis Misalignment and Unbalance in Rotating Machineries
}

\begin{abstract}
Due to the dynamic forces acting on the rotating machine parts, vibrations of different frequency and amplitude can occur on these parts. Very small vibrations cause resonance while large vibrations cause noise. Axis misalignment and unbalance on the rotating machine are important failures. Vibrations cause to axis misalignment and unbalance and transfer to the rolling bearings employing rotating shafts. In this study, the effects of axial misalignment and unbalance of a rotating machine-shaft system resulting from a rotating electric motor at a constant speed of $1380 \mathrm{rev} / \mathrm{min}$ were investigated experimentally. Eight experiments were performed on the rotating machine and the data were obtained by the aid of four-channel VIBROTEST 80 model FFT analysis data collection device. The total average of the vibration data was calculated by the Root Mean Square (RMS) method. In the light of these data, it was evaluated whether the vibration values are within accaptablelimits or not.
\end{abstract}

Keywords- Axis misalignment, Rotating Machinery, Unbalance, Vibration 


\section{GİRIş̧}

Mekanik sistem içerisinde hareketli parçaların bir araya gelmesiyle oluşmuş ve dönme işlemini yapan makinelere dönen makineler adı verilmektedir. Dönen makinelerin çalışma şartlarını ortaya çıkarmak için kullanılan parametreler; sıcaklık, yağ analizi, akıntı-sızıntılar, basınç, gürültü ve titreşimdir $[1,2]$. İşin pratiğinde, titreşimin olmaması oldukça zordur. Titreşim, hareketli parçaları olan makineye bağlı yapılarda dinamik kuvvetlerin etkisiyle makinenin bütün parçaları üzerinde çeşitli frekans ve genlikte oluşabilmektedir. Dönen makineler üzerinde zamanla aşınma ve hasara neden olan bu titreşimler, çoğu zaman makinenin uzun süre çalışmamasına da neden olabilmektedir. Genellikle boyutu çok küçük olan titreşimler rezonans meydana getirirken, boyutu büyük titreşimler gürültüye sebep olmaktadır [2].

Dönen makineler üzerinde birçok arıza gözlemlenmesine rağmen, eksen kaçıklı̆̆ı ve dengesizlik ihmal edilemeyecek öneme haiz arızalardan iki tanesi olarak karşımıza çıkmaktadır. Bu arızaların sebep olduğu titreşimlerin etkisi dönen miller vasıtası ile yuvarlanmalı yataklara aktarılır. Yataklardan titreşim değerlerinin alınması ile dönen makinelerin içyapısında meydana gelen değişimler kolaylıkla belirlenebilir. Bir algılayıcı tarafından alınan titreşim verileri zaman ve frekans ortamına ayrıştırılır. Dönen makinenin parçalarının zaman ve frekans ortamındaki davranışları bu yolla tayin edilebilmektedir. Değiş̧ik arızaların sebep olduğu titreşim frekansları da farklı olduğu için dönen bir makinede oluşan titreşim değerleri analiz edilerek belirlenebilir. Eksen kaçıklığı dönen makinelerde gerçek manada daima vardır. Genel itibariyle eksen kaçıklığının dönen millerde ve onları bağlayan kaplinler, V-kayışları, ara bağlayıcılar arasında olduğu düşünülmektedir. Fakat dönen milin yataklarında ve dönen makinenin diğer noktalarında da ortaya çıkabilmektedir [3]. Dönen makinelerin tüm donanımlarında meydana gelen mekanik bozulmaların yarısına yakın kısmını eksen kaçıklığı meydana getirmektedir. Mil, kaplin veya yuvarlanmalı yataklar (rulmanlar) merkezlerinden bütünüyle ayarlanmadığında eksenden kaçık hale gelebilmektedirler. Eksen kaçıklı̆̆ı iç, paralel ve açısal olmak üzere 3 çeşittir [4]. Dönen makinelerde dönen parçalar tarafından meydana getirilen bütün kuvvetlerin uyum halinde olmasına denge (balans) denir. Bu uyum durumu herhangi bir değişime maruz kalırsa balanssızlık ortaya çıkar. Balanssızlık dönen makinelerde görülen en geniş titreşim halidir [3]. Balanssızlık, ağırlık merkezi ile dönme merkezinin aynı olmaması durumunda ortaya çıkar [5]. Dengesizlik, dönen makinelerin devrinin yükselerek atalet kuvvetlerinin oluşmasına, akabinde gürültünün ortaya çıkmasına, makinelerin performansının ve ömrünün olumsuz bir şekilde etkilenmesine neden olabilmektedir. Dengesizliğe sebep olan atalet kuvvetlerinin etkisinin en aza indirilebilmesi için ya atalet kuvvetlerinin kaldırılması ya da kütle dengelemesinin yapılması gerekmektedir. Kütle dengelemesi yapılmasıyla birlikte, makinelerin hareketli kısımlarında oluşan atalet kuvvetlerinin bileşkesinin ve bu kuvvetlerin oluşturduğu momentlerinin bileşkesinin sıfır olması istenmektedir [6]. Dengesizlik statik, moment ve dinamik olmak üzere üç gruba ayrılmaktadır [7].

Dönen makinelerde titreşim analizi; yanlış doğrultulama, elektriki arızalar, dişli ve rulman hasarları, dengesizlik, eksenel hizasızlık, mekanik gevşeklik gibi durumlarda problemin kaynağını bulmak için kullanılan bir yöntemdir [8]. Titreşim analizi yaparken dikkate alınan iki bileşen vardır. Bunlar; frekans (belirli bir zaman periyodunda olayın oluş sayısı) ve genliktir (titreşim sinyalinin boyutu) [9]. Titreşimin meydana geldiği frekans, kusurun kaynağını gösterir. Başka bir anlatımla bilinen bazı kusurlar bazı frekanslarıda meydana getirmektedir. Titreşim sinyalinin genliği ise hatanın kapsamı hakkında bize bilgi verir. Genliğin yükselmesi ile hatanın yükseldiğinin sonucuna varılabilir. Dönen makinelerde kusur oluştuğunda ikaz olarak en iyi bilgiyi titreşim sinyalleri verirler [8].

Literatürde yapılan çalışmalarda; R. Gohar ve N. Aktürk iki adet açısal bilyeli rulman ile yataklanmış bir mil-rulman sisteminde geometrik olarak hatasız ve bilezikleri eksenden hizasız rulmanların titreşimlerini gözlemlemişlerdir [10]. Karadoğan ve Belek, laboratuvar ortamında bir fan üzerinde kontrollü bir şekilde gevşeklik, balanssızlık ve eksen kaçılı̆̆ı meydana getirerek, bu arızaların titreşim spektrumundaki durumlarını incelemiş̧lerdir [11]. Hariharan ve Srinivasan, eksen kaçıklığ kusurunu gözlemleyebilmek için dönen bir makine elemanına üçayaklı elastik kaplin kullanarak rulman yataklı bir şaft bağlantısı kurmuşlardır [12]. Xu ve Marangoni, eksen kaçıklığı ve dengesizlik tesiri altında esnek kaplin bağlantılı motor-rotor düzeneğinin reaksiyonlarını kriter alan bir düzenek üzerinde çalışmışlardır [13]. Köse, yaptığı çalışmada, dönen makinelerde dengesizlik, kaplin ayarsızlığı, mekanik çözülme, dişli, rulman, kaymalı yatak, kayış ve motor arızalarının FFT spektrum grafiklerini, örneklerle açıklamıştır [15]. Sinha ve arkadaşları, iki rulmanlı dönen bir makineyi esnek 
kaplin kullanarak bir elektrik motoruna bağlamışlar ve bu dönen makine üzerinde balanssızlık ve eksenel kaçıklıkdan dolayı oluşan etkileri incelemişlerdir. Tatbik ettikleri bu yöntemle oluşan hataların belirlenmesinde olumlu neticeler elde etmişlerdir [16]. Orhan yaptığ çalışmasında, fan ve pompa grubundan oluşan bir makine düzeneğinde belli zaman aralıklarında titreşim ölçümleri gerçekleştirmiştir. Test sonucu temin ettiği dataları frekans analizi yöntemi ile değerlendirerek makinelerde oluşabilecek balanssızlık, mekanik gevşeklik, eksenel ayarsızlık ve rulman kusurlarının daha oluşmaya başlamadan belirlenebildiğini göstermiştir [17]. Kalkat ve Yiğiter, iki ucundan rulmanlarla yataklandırdıkları şaft üzerinde dengesizlikleri gözlemlemişler ve dengeye getirilen bu düzenek üzerinde titreşimlerin azaldığını söylemişlerdir [18]. Kiran Kumar ve arkadaşları, dönen makinelerdeki balanssızlık kusurlarını belirleyebilmek için kurdukları bir rotor deney düzeneği üzerinde inceleme yapmışlardır [19].

Yapılan bu deneysel çalışmada ise $1380 \mathrm{~d} / \mathrm{d}$ sabit devirde dönen bir elektrik motorundan hareket alan ekseni kaçık imal edilmiş bir dönen makine sisteminin eksenel kaçıklık ve dengesizliğinin titreşime olan etkileri incelenmiştir. Dönen bir makine üzerinde 8 adet deney yapılmıştır. Her deney, $15 \mathrm{~s}$ süre için titreşim verilerinin toplam ortalaması, kare ortalamalarının karekökü (RMS) yöntemi ile belirlenmiştir. Dönen makinenin titreşim verileri, üç eksende yatay doğrultuda $\left(\mathrm{x}-\mathrm{Ch}_{1}\right)$, dikey doğrultuda $\left(\mathrm{y}-\mathrm{Ch}_{2}\right)$ ölçüm yapabilen Brüel \& $\mathrm{Kjaer} 4527$ model piezoelektrik ivmeölçer ile iki eksende $\left(\mathrm{Ch}_{1}-\mathrm{x}, \mathrm{Ch}_{2}-\mathrm{y}\right)$ alınmıştır. Tüm deneyler için yatay $(\mathrm{x})$ yönde $\mathrm{Ch}_{1}$ kanalından elde edilen $\mathrm{a}_{\text {rms }}$ titreşim değerlerinin en büyük olduğu, dikey (y) eksende $\mathrm{Ch}_{2}$ kanalından elde edilen

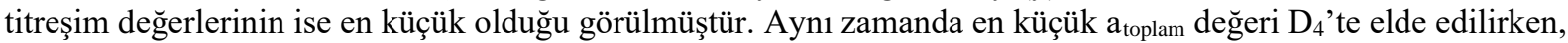
Ds'de, en yüksek atoplam değeri elde edilmiştir.

\section{II.MATERYAL VE METOT}

Tüm deneyler sabit devir sayısı (1380 d/d) kullanılarak elektrik motorundan mekanizmaya tahrik verilerek yapılmıştır. Şekil 1'de deney düzeneğinin resmi verilmiştir.

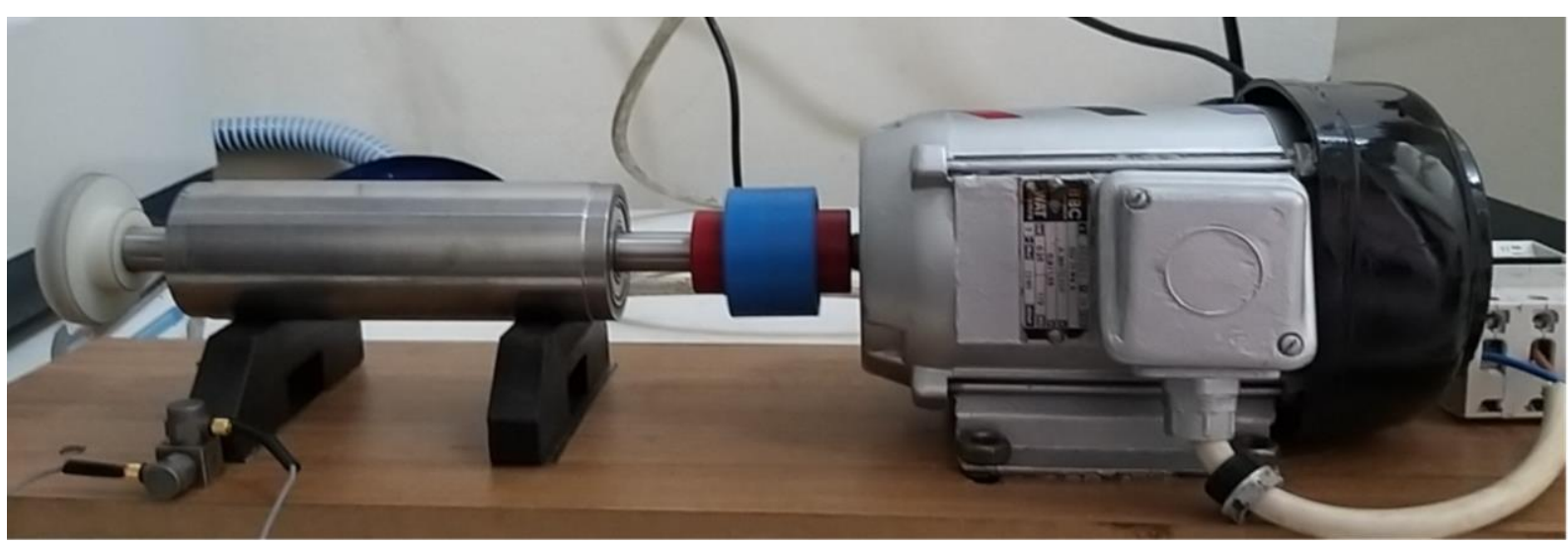

Şekil 1. Deney düzeneğinin resmi

Şekil 1'de görülen deney düzeneğinde; 8 adet deney yapılmış ve ivmeölçerler kullanılarak iki eksende (x-y) ölçüm alınmıştır. Yapılan deneyler şu şekildedir;

1. deney; yatak eksen kaçıklığında,

2. deney; yatak eksen kaçıklığında balanssızlık (balans ayar diski üzerinde tek somun ile),

3. deney; yatak eksen kaçıklığında balanssızlık (balans ayar diski üzerinde karşılıklı iki somun ile),

4. deney; yatak eksen kaçıklığında balanssızlık (balans ayar diski üzerinde iki somun yanyana),

5. deney; açısal eksen kaçıklığında ve yatak eksen kaçıklığında,

6. deney; açısal eksen kaçıklığında ve yatak eksen kaçıklığında balanssızlık (balans ayar diski üzerinde tek somun ile),

7. deney; açısal eksen kaçıklığında ve yatak eksen kaçıklığında balanssızlık, (balans ayar diski üzerinde karşılıklı iki somun), 


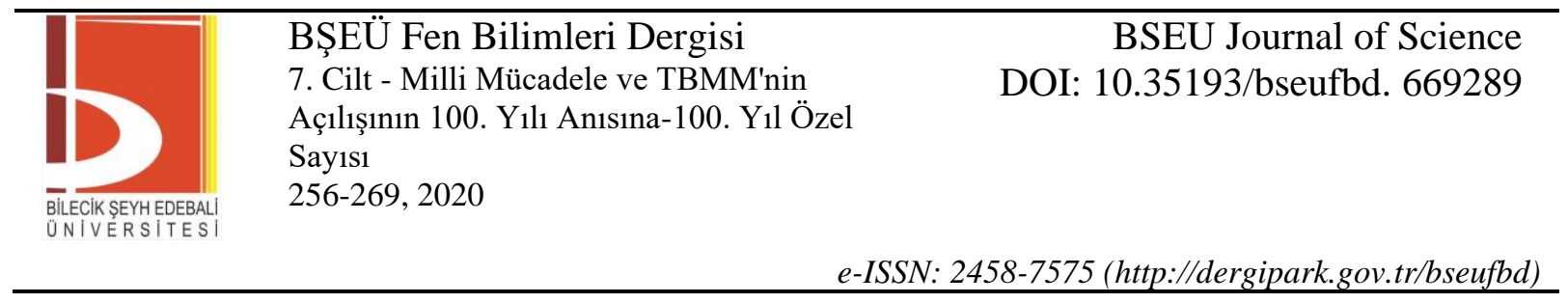

8. deney; açısal eksen kaçıklığında ve yatak eksen kaçıklığında balanssızlık, (balans ayar diski üzerinde iki somun yanyana) şeklinde yapılmıştır.

Şekil 2'de deney düzeneğinin şematik görünümü görülmektedir.

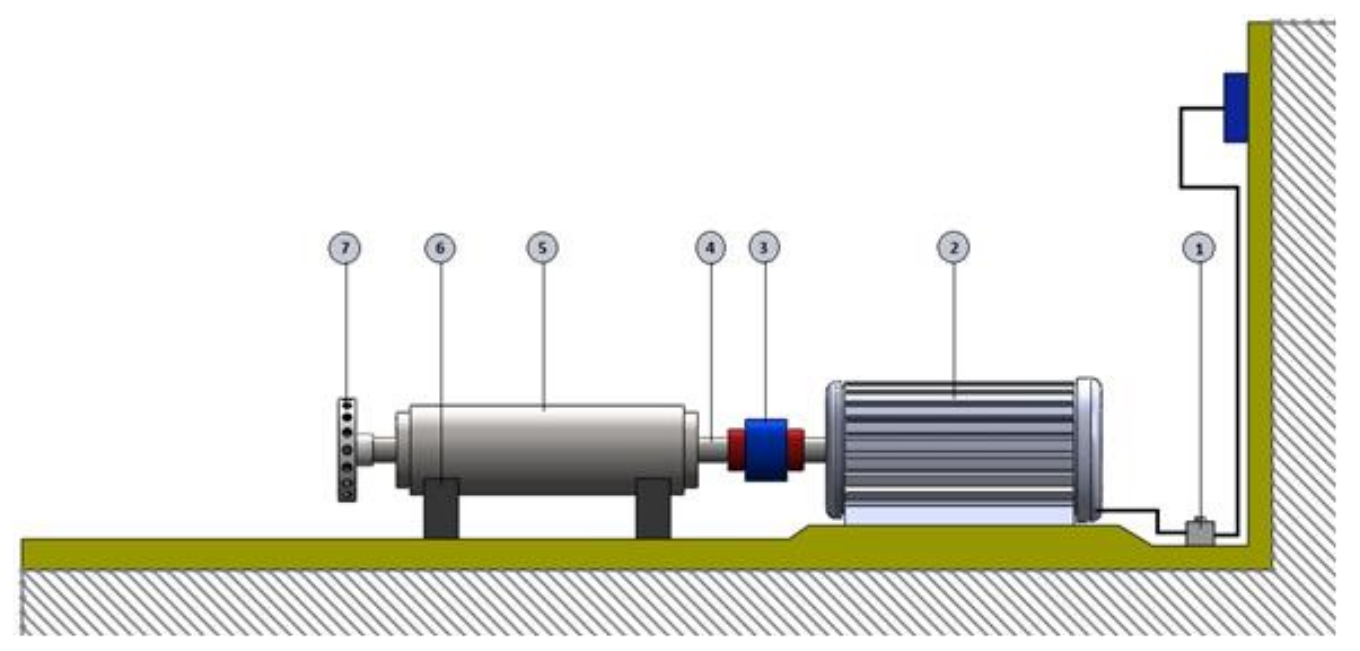

Şekil 2. Proje düzeneğinin şematik görünümü (1-K-otomat, 2-Elektrik motoru, 3- Kaplin, 4- Rulmanla yataklandırılmış mil, 5- Ekseni kaçık yuvarlanmalı rulman yataklarının bulunduğu etli boru, 6-V-yataklar, 7-Balans ayar diski)

Şekil 3'te ekseni kaçı yuvarlanmalı yatakların bulunduğu etli borunun kesit görünüşü ve ölçüleri görülmektedir.

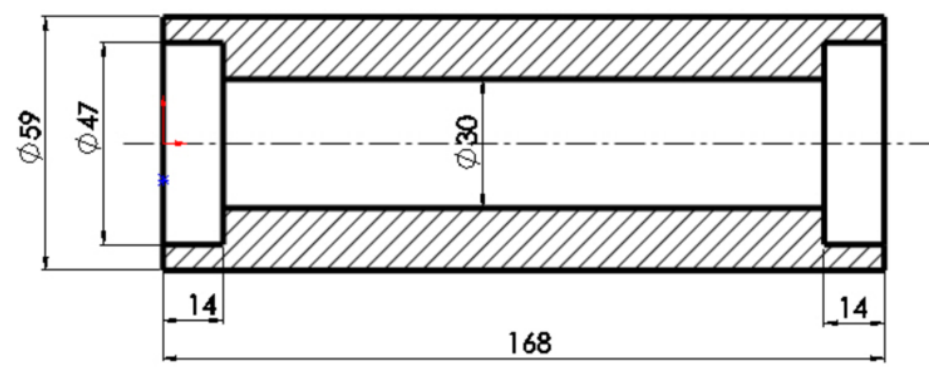

Şekil 3. Ekseni kaçık yuvarlanmalı yatakların bulunduğu etli borunun kesit görünüşü ve ölçüleri

Deneysel çalışmada kullanılan elektrik motorunun teknik özellikleri Şekil 4’te görülmektedir. 


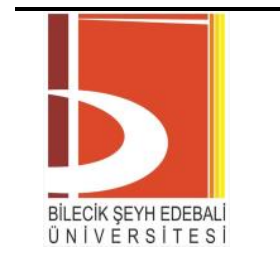

BŞEÜ Fen Bilimleri Dergisi

7. Cilt - Milli Mücadele ve TBMM'nin

Açılışının 100. Yılı Anısına-100. Yıl Özel

Say1s1

256-269, 2020

e-ISSN: 2458-7575 (http://dergipark.gov.tr/bseufbd)

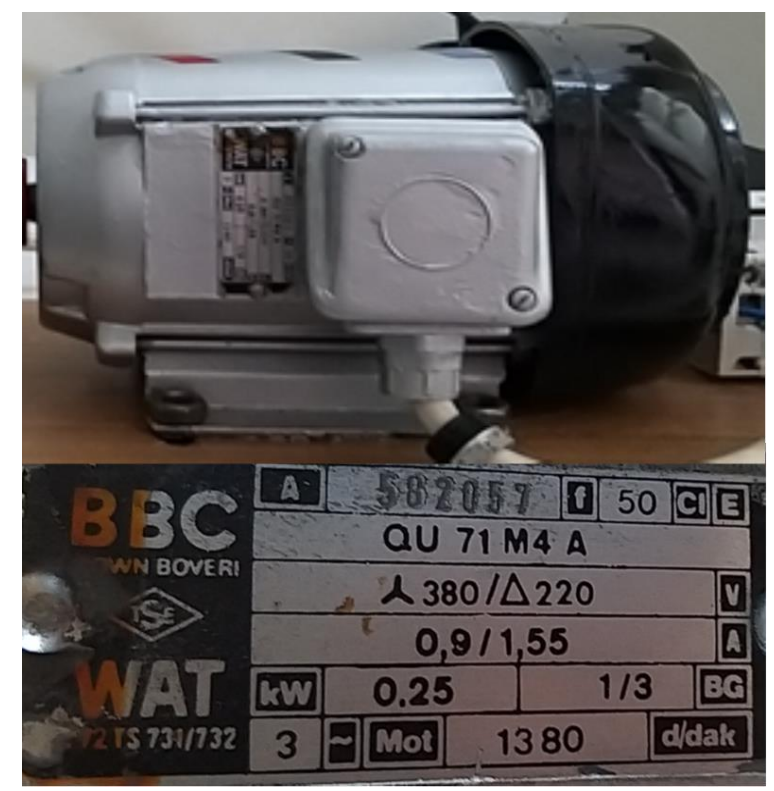

Sekil 4. Elektrik motorunun teknik özellikleri

Şekil 5’te titreşim ölçümünde kullanılan ekipmanlar görülmektedir. Titreşim ölçüm verileri, üç eksenli piezoelektrik ivmeölçere sahiptir.

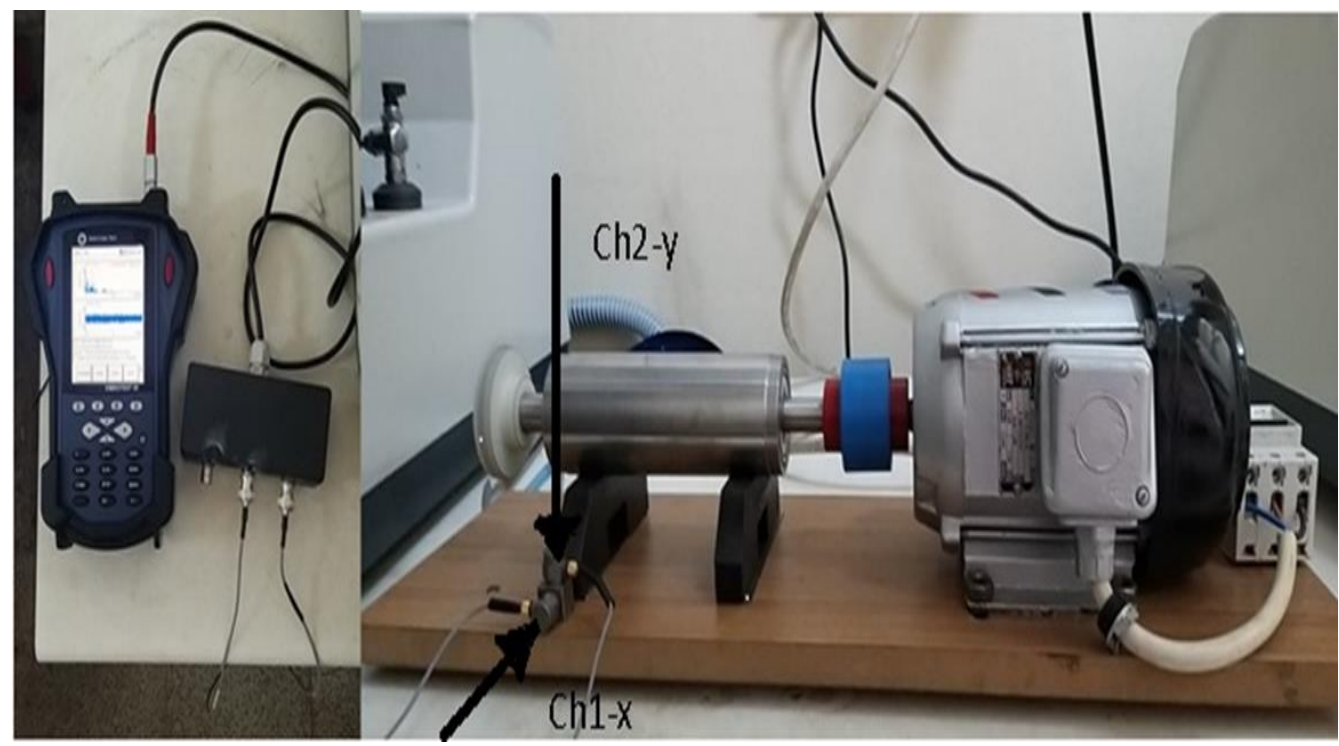

Şekil 5. Titreşim ölçümünde kullanılan ekipmanlar

Veriler dört kanallı VIBROTEST 80 model FFT analizi yapabilen veri toplama cihazı ile alınmıştır. Cihaz Brüel \& Kjaer yazılım ve donanım sistemine sahiptir. Veriler Hanning filtreleme yöntemi ile $6400 \mathrm{~Hz}$ çözünürlükte filtrelenerek analiz edilmiştir. Deneylerde $5 \mathrm{kHz}$ 'e kadar olan titreşim verileri alınmıştır. Titreşim verilerinin toplam ortalaması, kare ortalamalarının karekökü (RMS) yöntemi ile belirlenmiştir. Birimi m/ $\mathrm{s}^{2}$ dir. Makine titreşim verileri, yatay doğrultuda $\left(\mathrm{x}-\mathrm{Ch}_{1}\right)$, dikey doğrultuda $\left(\mathrm{y}-\mathrm{Ch}_{2}\right)$ ölçüm yapabilen Brüel \& Kjaer 4527 model piezoelektrik ivmeölçer ile iki eksende $\left(\mathrm{Ch}_{1}-\mathrm{x}, \mathrm{Ch}_{2}-\mathrm{y}\right)$ alınmıştır.

Deney düzeneğinde verileri almada kullanılan ivmeölçerlerin özellikleri Tablo1 ‘de verilmiştir. 


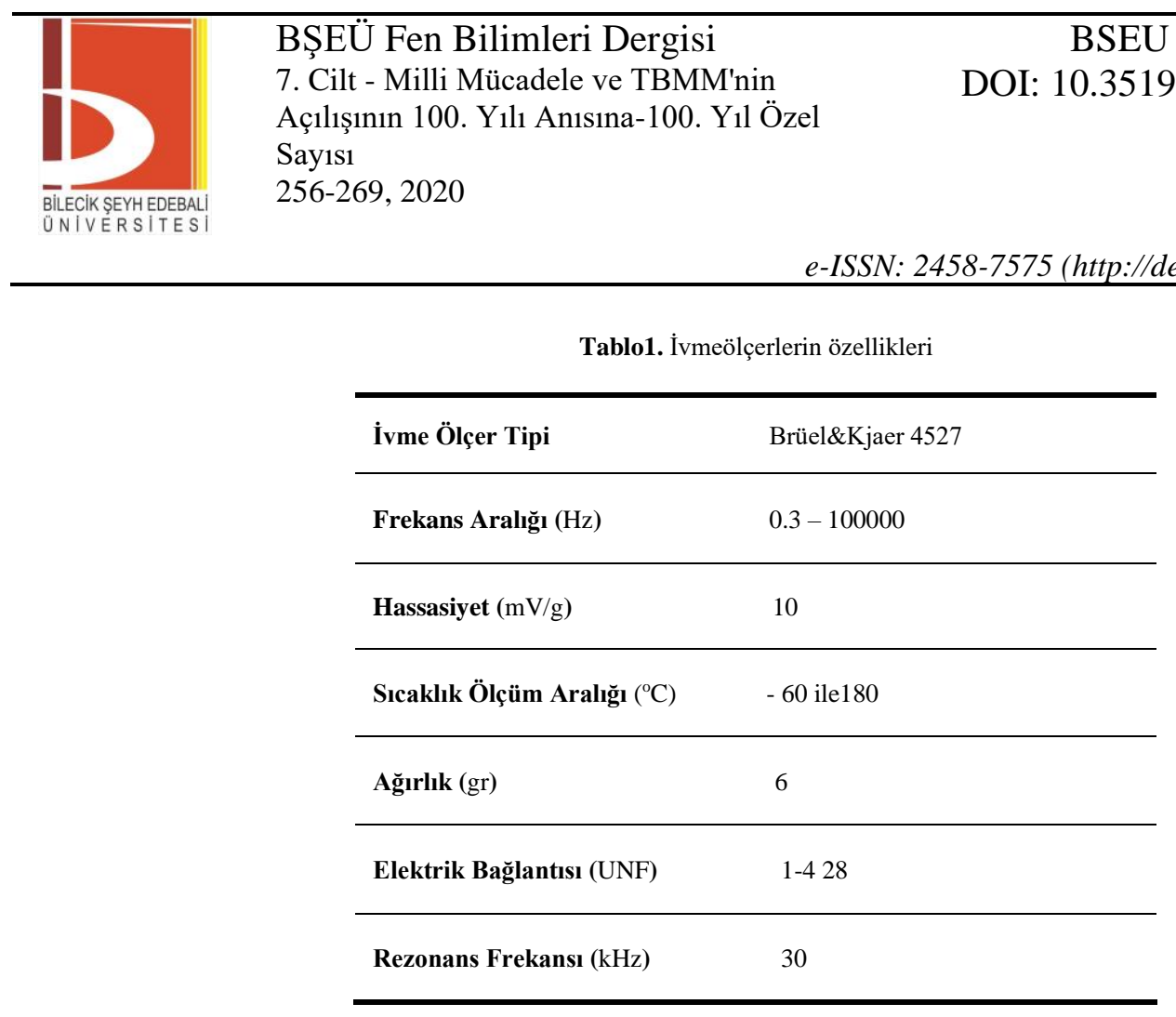

İvmeölçer dönen makinenin yataklandığı tabla üzerinde yatak hizasına yapıştırılarak montajı yapılmıştır. Şekil 6 'da ivme ölçerin yatay doğrultuda $\left(\mathrm{x}-\mathrm{Ch}_{1}\right)$ ve dikey doğrultuda $\left(\mathrm{y}-\mathrm{Ch}_{2}\right)$ eksenleri görülmektedir.

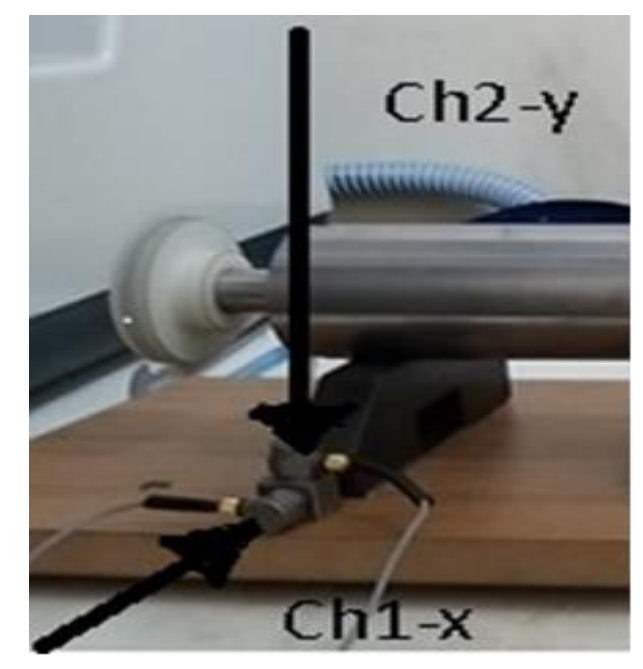

Şekil 6. İvmeölçerlerin yatay doğrultuda $\left(\mathrm{x}-\mathrm{Ch}_{1}\right)$ ve dikey doğrultuda $\left(\mathrm{y}-\mathrm{Ch}_{2}\right)$ eksenleri

\section{BULGULAR ve TARTIŞMA}

Deneysel çalışmada $1380 \mathrm{~d} / \mathrm{d}$ 'da sabit devirde dönen bir makine üzerinde 8 adet deney yapılmıştır. Deneylerde kullanılan parametreler ise Tablo 2' de verilmiştir. 
Tablo 2. Deneylerde kullanılan parametreler

\begin{tabular}{|c|c|}
\hline Deneyler & Deneylerde Kullanılan Parametreler \\
\hline $\mathrm{D}_{1}$ & Yatak Eksen Kaçıklığında \\
\hline $\mathrm{D}_{2}$ & $\begin{array}{l}\text { Yatak Eksen Kaçıklığında Balanssızlık (Balans Ayar Diski } \\
\text { Üzerine Tek Somun Takılarak) }\end{array}$ \\
\hline $\mathrm{D}_{3}$ & $\begin{array}{l}\text { Yatak Eksen Kaçıklığında Balanssızlık (Balans Ayar Diski } \\
\text { Üzerine karşılıklı iki Somun Takılarak) }\end{array}$ \\
\hline $\mathrm{D}_{4}$ & $\begin{array}{l}\text { Yatak Eksen Kaçıklığında Balanssızlık (Balans Ayar Diski } \\
\text { Üzerine iki Somun Yan yana Takılarak) }\end{array}$ \\
\hline $\mathrm{D}_{5}$ & 1 mm Açısal Eksen Kaçıklığında ve Yatak Eksen Kaçıklı̆̆ında \\
\hline $\mathrm{D}_{6}$ & $\begin{array}{l}1 \mathrm{~mm} \text { Açısal Eksen Kaçıklı̆̆ında ve Yatak Eksen Kaçıklığında } \\
\text { Balanssızlık (Balans Ayar Diski Üzerine Tek Somun Takılarak) }\end{array}$ \\
\hline $\mathrm{D}_{7}$ & $\begin{array}{l}1 \text { mm Açıssal Eksen Kaçıklığında ve Yatak Eksen Kaçıklığında } \\
\text { Balanssızlık (Balans Ayar Diski Üzerine karşılıklı iki Somun } \\
\text { Takılarak) }\end{array}$ \\
\hline $\mathrm{D}_{8}$ & $\begin{array}{l}1 \text { mm Açısal Eksen Kaçıklığında ve Yatak Eksen Kaçıklığında } \\
\text { Balanssızlık (Balans Ayar Diski Üzerine iki Somun Yan yana } \\
\text { Takılarak) }\end{array}$ \\
\hline
\end{tabular}

Deneylerden elde edilen titreşim verilerinin karşılaştırılabilmesi amacıyla, her bir deney için ivmeölçerin her bir kanalı ile ölçülen ivme değerlerinin kare ortalamalarının karekökü (rms) hesaplanmıştır. Her bir kanaldan elde edilen zaman bölgesi ivme değerlerinin ortalama karekök değerleri (rms), Eşitlik 1'de verilen denklem ile hesaplanmıştır [20, 21, 22, 23].

$$
a_{r m s}=\sqrt{\frac{1}{n} \sum_{k=1}^{n} a_{k}^{2}}
$$

Burada;

a : İvme değerlerinin ortalama karekökü $\left(\mathrm{m} / \mathrm{s}^{2}\right)$,

a : Zaman bölgesi verilerinin k'ıncı değeri (zaman bölgesinde tüm eksenlerde ivme ölçerden sayısal olarak $\mathrm{k}$ alınmıştır),

$\mathrm{n}=$ Zaman bölgesi ivme değerlerinin sayısı $(15$ s süre için $\mathrm{n}=32768)$

Tüm deneylerde iki eksende (x, y), ivmeölçerin $\mathrm{Ch}_{1}$ ve $\mathrm{Ch}_{2}$ kanallarında alınan titreşim verilerinin ortalama karekökü (arms), Eşitlik 1'e göre hesaplanmıştır. Tablo 3'de sabit devir sayısına bağlı olarak, tüm kanallardan elde edilen verilere göre hesaplanan $a_{\text {rms }}$ titreşim değerleri verilmiştir. 


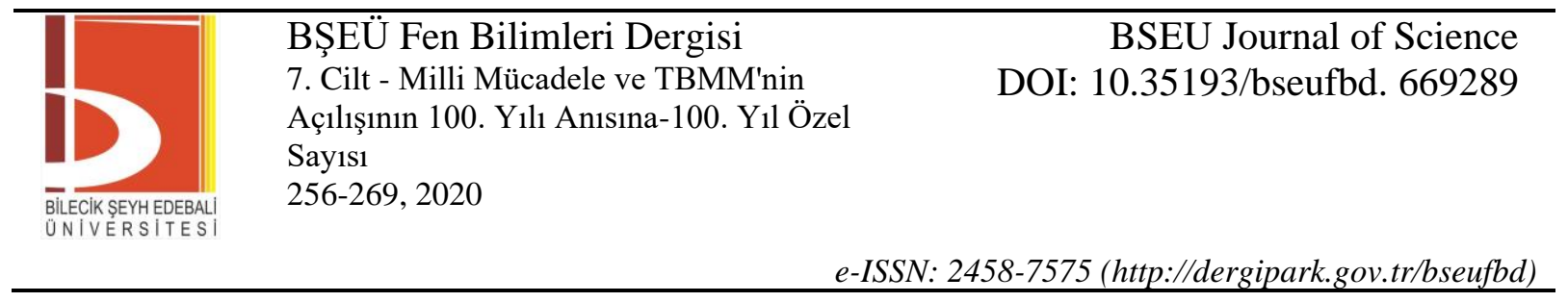

Tablo 3. Devre bağlı olarak, tüm kanallardan elde edilen verilere göre hesaplanan $\mathrm{a}_{\mathrm{rms}}$ titreşim değerleri

\begin{tabular}{lll}
\hline Deney Kodu & $\mathbf{C h}_{\mathbf{1}}(\mathbf{x})\left(\mathbf{m} / \mathbf{s}^{2}\right)$ & $\mathbf{C h}_{\mathbf{2}}(\mathbf{y})\left(\mathbf{m} / \mathbf{s}^{2}\right)$ \\
\hline $\mathrm{D}_{1}$ & 0.7867 & 0.6754 \\
\hline $\mathrm{D}_{2}$ & 0.6447 & 0.4477 \\
\hline $\mathrm{D}_{3}$ & 0.6738 & 0.5136 \\
\hline $\mathrm{D}_{4}$ & 0.6277 & 0.4362 \\
\hline $\mathrm{D}_{5}$ & 0.7575 & 0.6737 \\
\hline $\mathrm{D}_{6}$ & 0.8442 & 0.6400 \\
\hline $\mathrm{D}_{7}$ & 0.9024 & 0.6672 \\
\hline $\mathrm{D}_{8}$ & 0.9529 & 0.6810 \\
\hline
\end{tabular}

Tüm deneyler için $\mathrm{x}$, y eksenlerinde genel olarak, $\mathrm{a}_{\mathrm{rms}}$ titreşim değerleri $\mathrm{D}_{4}$ 'e kadar azalıp, daha sonra artmaya başlamıştır.

Tüm deneyler için yatay (x) yönde $\mathrm{Ch}_{1}$ kanalından elde edilen titreşim değerlerinin en büyük olduğu, dikey (y) eksende $\mathrm{Ch}_{2}$ kanalından elde edilen titreşim değerlerinin ise en küçük olduğu Şekil 7'de görülmektedir. 

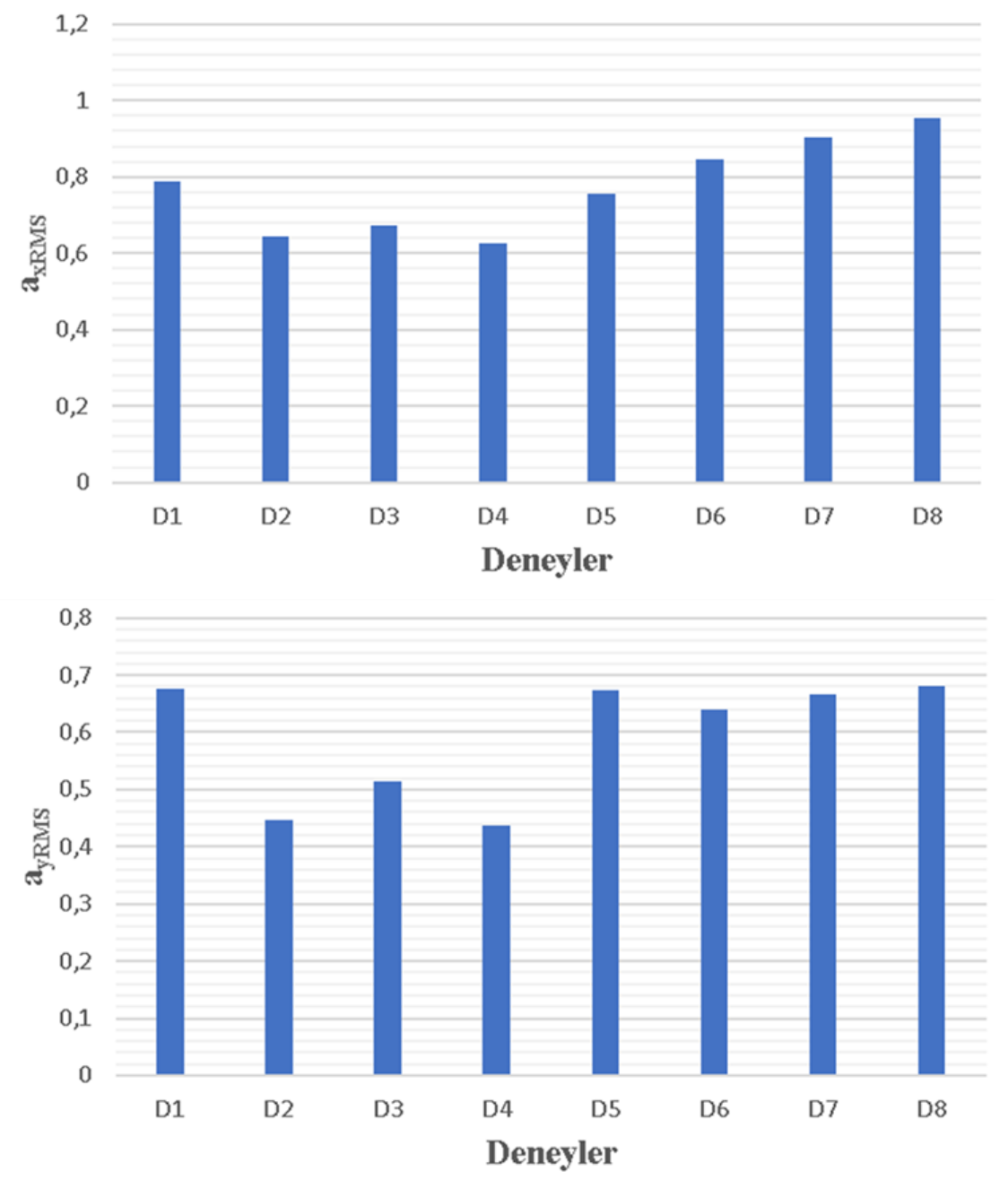

Şekil 7. Tüm deneyler için yatay (x) yönde $\mathrm{Ch}_{1}$ kanalından ve dikey (y) yönde $\mathrm{Ch}_{2}$ kanalından elde edilen titreşim değerleri

$\mathrm{Bu}$ durum, atalet kuvvetlerinin yatay eksende en büyük, dikey eksende ise en küçük olduğunu ve makinenin yatay ekseninin dikey eksenine göre daha fazla salınım yaptığını göstermektedir [24].

Dönen makinenin sabit $1380 \mathrm{~d} / \mathrm{d}$ 'sı için, tüm eksenlerden alınan titreşim verileri Eşitlik 2 kullanılarak düzenlenmiş ve toplam ortalama titreşim değerleri ( $\left.a_{\text {toplam }}\right)$ elde edilmiştir.

$$
a_{\text {topiam }}=\sqrt{a_{r m s(x)}^{2}+a_{r m s(y)}^{2}}
$$

Tablo 4'de görüldüğü gibi tüm eksenlerdeki atoplam değerlerini elde etmek için, her bir eksendeki kare ortalamalarının karekökü (rms) ivme değerleri kullanılmıştır [20, 21, 22, 23]. 
Tablo 4. Tüm eksenlerdeki $\mathrm{a}_{\text {toplam }}$ değerleri

\begin{tabular}{ll}
\hline Deney Kodu & $\mathbf{a}_{\text {toplam }}\left(\mathbf{m} / \mathbf{s}^{2}\right)$ \\
\hline $\mathrm{D}_{1}$ & 1.03694 \\
\hline $\mathrm{D}_{2}$ & 0.78491 \\
\hline $\mathrm{D}_{3}$ & 0.84726 \\
\hline $\mathrm{D}_{4}$ & 0.76421 \\
\hline $\mathrm{D}_{5}$ & 1.01382 \\
\hline $\mathrm{D}_{6}$ & 1.05946 \\
\hline $\mathrm{D}_{7}$ & 1.1223 \\
\hline $\mathrm{D}_{8}$ & 1.17129 \\
\hline
\end{tabular}

Burada; atoplam toplam titreşim ortalama değeri, $a_{r m s}(x)$ ve $a_{r m s}(y)$, ise sırasıyla yatay ve dikey yönlerdeki kare ortalamalarının karekökü (rms) ivme değerleridir.

Şekil 8'de $\mathrm{D}_{1}, \mathrm{D}_{2}, \mathrm{D}_{3}, \mathrm{D}_{4}, \mathrm{D}_{5}, \mathrm{D}_{6}, \mathrm{D}_{7}$ ve $\mathrm{D}_{8}$ için elde edilen, atoplam değerlerinin grafiği görülmektedir.

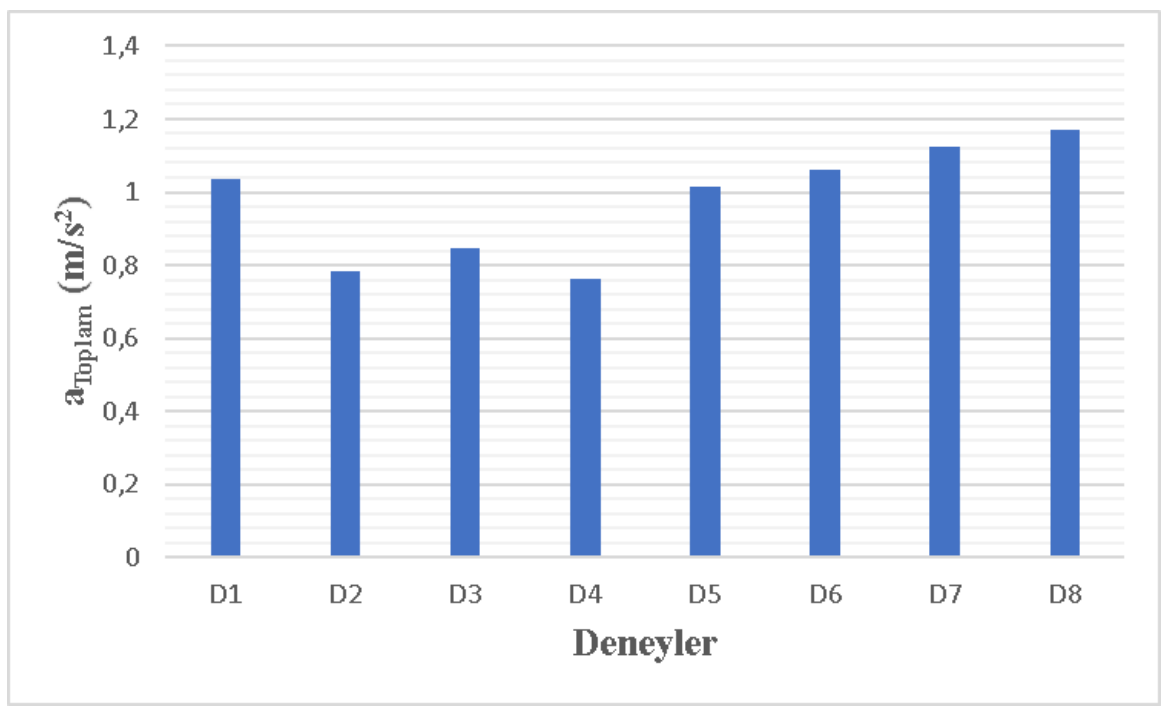

Şekil 8. $D_{1}, D_{2}, D_{3}, D_{4}, D_{5}, D_{6}, D_{7}$ ve $D_{8}$ için elde edilen, $a_{\text {toplam değerlerinin grafiği }}$

En küçük $\mathrm{a}_{\text {toplam }}$ değeri $\mathrm{D}_{4}$ 'te elde edilirken, $\mathrm{D}_{8}$ 'de, en yüksek $\mathrm{a}_{\text {toplam }}$ değeri elde edilmiştir. $\mathrm{D}_{1}$ deneyinde ortaya çıkan titreşim ortalama değeri, $\mathrm{D}_{2}, \mathrm{D}_{3}, \mathrm{D}_{4}$ ve $\mathrm{D}_{5}$ 'deki verilere kıyasla $\% 32, \% 22, \% 36$ ve \% 2 oranlarında daha yüksek olduğu ve $\mathrm{D}_{6}, \mathrm{D}_{7}$ ve $\mathrm{D}_{8}$ 'deki verilere göre ise $\% 2, \% 8$ ve $\% 11$ oranlarında daha düşük 
değerler olduğu görülmüştür. Titreşim karakteristikleri, makine performansı hakkında en önemli ve detaylı bilgileri verebilmektedir [1]. Hareketli parçaları olan makinelerde ve makineye bağlı olan yapılarda dinamik kuvvetlerin etkileri nedeniyle oluşan titreşim sonucunda dönen makine sistemlerinde eksen kaçıklığı dengesizlik vb. oluşabilir. Bu nedenle bu sistemlerin bileşenleri farklı frekans ve genlikte titreyebilir. Oluşan bu titreşim, sistemin bağlantı noktalarından parçayı zorlayacak şekilde sistemin yapısal özelliklerini etkilemektedir. Özellikle oluşan titreşim, sistemin doğal frekansları ile çakışması durumunda sistemin tasarım limitlerini zorlamaya başlayacaktır. Parçanın çalışma ömrü titreşimin bu etkileri ile azalmakta, parçanın oluşturduğu titreşim ve ses zamanla artmaktadır. Oluşan titreşimlerin sonucunda ise aşınma ve hasar oluşabilmektedir [2,25]. Temel bir titreşim analizi ile rulmanlarda hasar ve bozulma, dişlilerde hasar, mekanik gevşeklikler, aşınma, dönen millerde eksen kaçıklığı ve dengesizlik gibi mekanik arızaların tespiti yapılabilir. Bunlara ek olarak paralel/eksenel kaçıklık ve balanssızlık (unbalance) tespitinin yapılabilmesi ile erken oluşabilecek mil ve rulman hasarları da önlenebilmektedir. Titreşim analizi milin eksen kaçıklığının giderilmesi ve özensiz balans alınması gibi hatalı bakım uygulamalarının tespitinde kullanılmaktadır [26]. Bu çalışmada elde edilen veriler sınır değerler arasında olduğundan rezonans (tınlaşım) oluşmayacağı dolayısı ile yıkıcı bir hasara sebebiyet vermeyeceği düşünülmektedir [27].

\section{SONUÇLAR ve ÖNERILER}

$\mathrm{Bu}$ çalışmada titreşim analizi yöntemi kullanılarak 8 deney yapılmış ve deneylerden titreşim verileri elde edilmiştir. Mil yatak sistemlerinde eksen kaçıklığı, kaçıklığın büyüklüğüne bağlı olarak rulmanlara ek olarak statik ve dinamik yükler etki etmesine neden olmaktadır. Bu çalışmada titreşim analizi yöntemi kullanılarak yapılan deneysel çalışmada elde edilen titreşim verileri analiz edilmiştir. Dengesizlik ve eksen kaçıklığı ile bunların neden olduğu titreşim arasındaki ilişki açıklanmıştır. Sonuç olarak, dönen makine sisteminde yatay doğrultuda $\left(\mathrm{x}-\mathrm{Ch}_{1}\right)$ elde edilen $\mathrm{a}_{\mathrm{rms}}$ değerleri dikey doğrultuda $\left(\mathrm{y}-\mathrm{Ch}_{2}\right)$ elde edilen değerlerden daha büyük çıkmıştır. Deney parametrelerine göre her iki eksende $\mathrm{D}_{4}$ 'e kadar bir düşme yaşanmış ve $\mathrm{D}_{5}$ 'ten sonra her iki eksende de değerler kademeli olarak artmıştır. atoplam değerleri de $\mathrm{D}_{1}$ 'den itibaren $\mathrm{D}_{4}$ 'e kadar düşmüş bu deneyden sonra değerlerde artış görülmüştür. Bu da gösteriyor ki farklı değişken parametreler kullanılsaydı ya da elektrik motorunun devri sabit değilde kademeli olarak arttırılsaydı, bu durum daha fazla titreşime neden olacak ve gürültü değerlerini de daha fazla arttırabilecekti. Bu durum aynı zamanda dönen millerin yataklandığı rulmanlar üzerine daha fazla ve düzensiz yük binmesine ve zaman geçtikçe rulman arızalarına neden olabilecek, belki de dönen makine sisteminin rezonansa girip kullanılamaz hale gelmesine neden olacaktır [2, 27, 28-31]. Yapılan çalışma, dönen makinelerde ortaya çıkan eksen kaçıklığı ve dengesizliğgi, titreşim analizi tespiti ile uğraşanların bilgi birikimine ve literatüre önemli katkı sağlayacağı düşünülmektedir.

\section{TEŞEKKÜR}

Yazarlar, bu çalışmanın gerçekleştirilmesinde her türlü katkı ve desteklerini sağlayan Düzce Üniversitesi Teknoloji Fakültesi Makine ve İmalat Mühendisliği Bölüm Başkanı Prof. Dr. Suat SARIDEMIR'e ve Düzce Borsa İstanbul Mesleki ve Teknik Anadolu Lisesi Makine Teknolojisi Alan Şefi Yılmaz IŞIKAN'a teşekkür eder.

\section{KAYNAKLAR}

[1] Toprak, T.\& Belek T. (1991). Endüstriyel Tesislerde Makine Performansının İzlenmesi ve Bilgisayar Destekli Bakım Planlaması. Brüel \& Kjaer Teknik Personel Eğitimi Kurs Notları., İTÜ Makina Fakültesi.

[2] Altuntaş, Ö. (2007). Hava Araçlarında Dönel Makinaların Titreşimi ve Önemi. Yüksek Lisans Tezi, Anadolu Üniversitesi, Fen Bilimleri Enstitüsü, Eskişehir.

[3] Orhan, S. (2003). Dönen Makinelerde Oluşan Arızalar ve Titreşim İlişkisi. Teknoloji, Yıl 6, sayı 3-4, 41-48.

[4] Karahan, M. M. F. (2005). Titreşim Analizi ile Makinalarda Arıza Teşhisi. Yüksek Lisans Tezi, Manisa Celal Bayar Üniversitesi, Fen Bilimleri Enstitüsü, Manisa. 
[5] Engür, A. İ. (2007). Kestirimci Bakımda Titreşim Analizi. Mühendis ve Makine, Cilt:48, Sayı: 570.

[6] Şanverdi, S. (2012). Dönen Makinalarda Slvı Halkalı Dengeleme Sistemleri: Modelleme ve Analiz. Yüksek Lisans Tezi, İstanbul Teknik Üniversitesi, İstanbul.

[7] Uysal, V.\& Morgül, Ö. K. (2015). Dönen makinelerdeki dengesizlik (balanssızlık) arızasının titreşim analizi ve faz açısı yardımıyla teşhisi. SAÜ Fen Bil Der 19. Cilt, 3. Sayı, s. 245-256.

[8] Kaplan, K., Bayram S., Kuncan M., \& Ertunç, H.M. (2012). Otomatik Kontrol Ulusal Toplantısı”, TOK2012, 11-13 Ekim, Niğde.

[9] Kalyoncu, M. (2006). Titreşim Analizi ile Makina Elemanları Arızalarının Belirlenmesi. Mühendis ve Makine, Cilt: 47 Sayı: 552.

[10] Gohar, R., \& Akturk, N. (1998). Vibrations associated with ball bearings. ImechE, 43-64.

[11] Karadoğan, H., \& Belek, T. (1988). Endüstriyel vantilatörlerde uyarıcı dinamik bakım. 3. Ulusal Makina Teorisi Sempozyumu, DEU, İzmir, 94-105.

[12] Hariharan, V., \& Srinivasan, P. (2009). Vibration analysis of misaligned shaftball bearing system. Indian Journal of Science and Technology, 2 No.9, 45-50.

[13] Xu, M., \& Marangon1 R.D. (1994). Vibration analysis of a motor-flexible coupling-rotor system subject to misalignment and unbalance, Part I: theoretical model analysis. Journal of Sound and Vibration, $663-679$.

[15] Köse, K. R. (2003). Makina Arızalarının Belirlenmesinde Titreşim Analizi. Mühendis ve Makine, Cilt:45 Say1:538.

[16] Sinha, J.K., Lees A.W., \& Friswell M.I. (2004). Estimating unbalance and misalignment of a flexible rotating machine from a single run-down. Journal of Sound and Vibration, 272, 967-989.

[17] Orhan S. (2002). Rulmanlarla Yataklanmış Dinamik Sistemlerin Titreşim Analizi ile Kestirimci Bakımı. Doktora Tezi, Fen Bilimleri Enstitüsü, Kırıkkale Üniversitesi, Kırıkkale.

[18] Kalkat, M., \& Yiğiter N. (2000). Kütle dengesizliğinden kaynaklanan şaft Mekanik titreşimlerinin yapay sinir ă̆lart ile analizi. Niğde Üniversitesi Mühendislik Bilimler Dergisi, Cilt 4, Sayı 1, 51-59.

[19] Kumar, K.B., Diwakar G., \& Satynarayana, M. R. S. (2012). Determination of Unbalance in Rotating Machine Using Vibration Signature Analysis. International Journal of Modern Engineering Research (IJMER), 2(5), 3415-342.

[20] Taghizadeh-Alisaraei A., Ghobadian B., \& Tavakoli-Hashjin T, Mohtasebi S.S. (2012). Vibration analysis of a diesel engine using biodiesel and petrodiesel fuel blends. Fuel;102: 414-422.

[21] Uludamar, E., Tosun E., \& Aydın K. (2016). Experimental and regression analysis of noise and vibration of a Compression ignition engine fuelled with various biodiesels. Fuel; 177:326-333.

[22] Saridemir S, 2013, "The effect of dwell angle on vibration characteristics of camshaft bearing housings", Journal of Mechanical Science and Technology; 27 (12):3571-77

[23] Sarıdemir, S., \& Saruhan, H. (2014). Experimental analysis of maximum valve lift effects in cam-follower system for internal combustion engines. Journal of Mechanical Science and Technology; 28 (9): 34433448.

[24] Sarıdemir, S., Alçelik, N., \& Uygur, İ. (2016). Biyodizel-Dizel Yakıt Karışımlarının Motor Titreşimine Olan 
Etkisinin İncelenmesi. Makine Teknolojileri Elektronik Dergisi, Cilt: 13, No: 4, (103- 110).

[25] Analizsimulasyon.com internet sitesi (2019). Dönen Parçaların Titreşim ve Akustik Açıdan İncelenmesi. http://analizsimulasyon.com/donen-parcalarin-titresim-ve-akustik-acidan-incelenmesi/ (29.12.2019).

[26] Ayan, Ö. A. (2019). Döner Makine Elemanların Titreşim Analizi ile Kestirimci Bakımı. Yüksek Lisans Tezi, Trakya Üniversitesi, Fen Bilimleri Enstitüsü, Edirne.

[27] Kam, M. (2016). Kriyojenik Isşlem Görmüş̧ Millerin Dinamik Davranışlarının Deneysel Analizi. Doktora Tezi, Düzce Üniversitesi, Fen Bilimleri Enstitüsü, Düzce.

[28] Esen, İ., Mızrak, C., \& Polat, R. (2011). Yuvarlanmalı Yataklarda Eksen Kaçıklı̆̆ının Rulman Üzerine Etkilerinin İncelenmesi. 15. Ulusal Makine Teorisi Sempozyumu, Niğde Üniversitesi Mühendislik Fakültesi, 16-18.

[29] Saruhan, H., \& Kam, M. (2016). Experimental spectral analysis of split sleeve bearing clearance effect on a rotating shaft system. Makine Teknolojileri Elektronik Dergisi; 13(4): 1-8.

[30] Kam, M., Saruhan, H., \& Güney, T. (2016). Kriyojenik işlem ve sıcak dövme işlemi uygulanmış millerin deneysel titreşim analizi. İleri Teknoloji Bilimleri Dergisi; 5(3): 21-30.

[31] Kam, M., \& Saruhan, H. (2019). Kriyojenik işlem uygulanmış millerin yuvarlanmalı ve kaymalı yataklarda deneysel titreşim analizi. Politeknik Dergisi; 22(1): 129-134. 